\title{
Research on the Problems and Counter measures of Training Mode of Intellectual Property Talents in China
}

\author{
Zhao Lingrui \\ National Academy of Innovation Strategy, China Association for Science and Technology, Beijing \\ 100863, China
}

Keywords: Intellectual property talents, Training mode, Practical course.

\begin{abstract}
With the development of intellectual property undertaking in China, the number of intellectual property talents we need is highly increasing. While the deficiency of training mode of intellectual property talents, the gap between demand and supply of intellectual property talents in China is becoming more and more large. This paper analyzes the main problems existing in the training mode of intellectual property talents in China. The analysis shows that the diversified training mechanism of intellectual property talents is deficient, and it is difficult to train compound intellectual property talents, and teachers and practical courses which meet the market demand are insufficient. In order to tackle these problems, it is crucial to adopt various modes, including innovating the training mechanism of intellectual property talents, optimizing the layout of intellectual property disciplines in colleges, speeding up the construction of the teaching staff for intellectual property talents, and adding practical courses and improving teaching methods.
\end{abstract}

\section{Introduction}

Intellectual property talents are the first resource to support the development of intellectual property undertaking, and provide an important intellectual foundation for the construction of a powerful intellectual property nation [1]. By the end of the twelfth five-year plan, China had more than 150,000 intellectual property professionals, and the number of intellectual property practitioners were more than 500,000. With the continuous improvement of talents' ability and quality, a system of intellectual property talents with reasonable echelon and complete categories had been basically formed. According to the requirements of the thirteenth five-year talent planning of the state intellectual property office, by the end of 2020, the number of intellectual property professionals will reach more than 500,000, and the number of intellectual property practitioners nationwide will exceed 1 million, among which more than 300,000 are enterprise intellectual property talents, accounting for $60 \%$. Thus, the gap between demand and supply of intellectual property talents in China is still relatively large.

Nowadays, intellectual property talents have become a growing talent category in the new era. In the occupational classification of the People's Republic of China (2015 edition), 347 occupations were added, including the subcategory of intellectual property professionals (GBM20612), which consists of 8 related occupations, such as patent agency professionals, patent examination professionals, patent management professionals, patent information analysis professionals, and so on. The revision of occupation code releases an important signal that the demand of intellectual property talents in society would be huge, and indicates that intellectual property had a clear career direction. The degree of specialization, refinement and professionalization of intellectual property talents is becoming higher and higher, which will put forward higher requirements for the level and scale of intellectual property talents training.

According to statistics, 334,688 pieces of recruitment information on intellectual property talents had been released by 35,624 enterprises and institutions, from January to July 2018, which increase by 220,624 pieces. Most of jobs are demand for professionals, in another words, market demand for high-level intellectual property talents is growing with each passing day. Especially with the development of new technology revolution, the application of new technology will put forward higher requirements for the intellectual property talents. In order to tackle challenges at home and 
abroad when carrying out powerful intellectual property nation strategy, China needs not only high-end talents who can participate in international competition and have an international vision, but also elite talents who can adapt to large and medium-sized enterprises and practical talents who can serve numerous small and medium-sized enterprises and solve their actual needs. Therefore, China is facing a real contradiction between less talent accumulation and greater demand, which will be more prominent with the construction of powerful intellectual property nation.

\section{Problems existing in the training mode of intellectual property talents in China}

In the development of intellectual property undertaking in China, problems existing in the scale, quality, structure and distribution of intellectual property talents are mainly caused by the deficiency of its training mode. At present, there are two ways to train intellectual property talents in China, one is continuing education of on-the-job training, and the other is professional degree education of intellectual property in colleges and research institutes. In fact, most intellectual property practitioners are trained through degree education [2]. Up to March 2018, there are 35 universities in China have established intellectual property colleges, and 76 universities have offered intellectual property (law) undergraduate major. In general, there are three main problems in the training mode of intellectual property talents in China.

\subsection{Lack of diversified training mechanism of intellectual property talents}

In China, the vast majority of intellectual property talents are trained by universities and research institutions, the role of enterprises and other organizations is often weakened, especially enterprises. Enterprises are in the principal position in technology innovation and national intellectual property strategy, and they are always be the centralism place where needs more intellectual property talents, while the status of enterprises in the training system of intellectual property talents has not been fully valued. At present, enterprises, whose education and training level is limited, are short of intellectual property professionals, and lack of information channels to build a good relationship between enterprises and the government, educational and scientific research institutions. It is urgent to establish a training mechanism of intellectual property talents that combines extensive popularization and key training in enterprises, so as to accelerate the training of practical talents.

\subsection{The difficulty in training compound intellectual property talents}

Intellectual property is a discipline that covers law, management, science and technology, economy, negotiation skills, etc. [3], and its practical application is very crucial. The cultivation of intellectual property talents in China is mainly based on undergraduate education, and intellectual property is regarded as a characteristic major of law to develop. The training of high-level intellectual property talents is mainly based on the master's degree education of intellectual property, which mainly relies on the disciplines of law and management to recruit academic master's degree and doctor's degree of intellectual property, and on the disciplines of law, business administration and engineering to recruit professional master's degree of intellectual property. By this training mode, a complete and systematic intellectual property knowledge system cannot be established, and it is difficult to cultivate compound intellectual property talents needed by the society.

\subsection{Lack of teachers and practical courses which meet the market demand}

Currently, the number of experienced teachers for intellectual property talents training in China is small, and there is no interdisciplinary teaching team and no part-time teachers with practical experience hired in the training of intellectual property talents. In intellectual property teaching process, a traditional teaching method is used, which is mainly lecturing and supplemented by case discussion. Teachers only pay attention to transfer knowledge to students, but ignore their absorption and internalization. The curriculum content centers on law and intellectual property courses, and there are few practical courses about practical work [4]. The lack of training and cultivation of talents' 
practical ability leads to the deficiency of talents' practical ability, which is not matched with the demand of enterprises for high-level talents.

\section{Suggestions on improving training mode of intellectual property talents}

In order to meet the needs of the development of intellectual property undertaking in China, it is urgent to establish a specialized training system that takes the vocation as its orientation and cultivates high-level applied compound intellectual property talents as its goal in the new era. The intellectual property profession includes intellectual property research, intellectual property administration, enterprise intellectual property management, intellectual property agency service, intellectual property legal affairs and intellectual property examination [5]. In the training of intellectual property talents, rational allocation of advantages should be made based on different types of profession. Under the background of building a strong intellectual property country in China, various modes should be adopted to cultivate intellectual property talents for innovation, and it can be improved from the following aspects.

First of all, the training mechanism of intellectual property talents should be innovated and the position of enterprises in talent training should be strengthened. The joint training mechanism between universities and enterprises should be improved and their strategic cooperation should be deepened. We need to explore continuously new training mechanisms of intellectual property talent through the integration of industry and education, and effectively align talent training with social needs. Enterprises should intensify the on-the-job training of scientific and technological talents, and select the on-the-job employees with discipline basis and development intention to carry out intellectual property education and training. Enterprises should carefully plan and systematically carry out the training of intellectual property related skills, provide their employees with frontier knowledge of the discipline and opportunities to enhance practical ability, so as to cultivate applied intellectual property talents urgently needed by enterprises.

Then, the layout of intellectual property disciplines in universities should be optimized, and to meet the market demand more master's and doctor's degrees should be added. The development of legal science should be steadily promoted and the integration with intellectual property related disciplines should be strengthened. We need to promote actively the development of intellectual property in management or economics, which is characterized by strategic management, early warning, patent layout, intelligence analysis and value assessment. We need to create a batch of master's and doctor's professional degrees of intellectual property, integrating operation, management and law, and explore a new way to cultivate applied intellectual property talents, so as to cultivate talents who are interdisciplinary, cross-disciplinary and practical.

Next, the construction of the teaching staff for intellectual property talents should be speeded up and practical experts should be hired to be university teachers. We need to steadily promote the training of teachers of intellectual property in the legal field, increase the training of teachers of intellectual property in other disciplines through appropriate policy preferences, such as adding doctoral enrollment targets, and strengthen the continuous professional education of intellectual property talents at all levels. Many practical experts from the front line of intellectual property work can be excellent resources for the "double-qualified" teacher structure in the professional degree education of intellectual property. Lawyers, patent agents, patent assessors and intellectual property planners with solid theoretical knowledge, high practical skills and rich practical experience should be invited to teach practical courses.

Finally, practical courses should be added according to the needs of training, and teaching methods should be improved combined with the latest technology. On the basis of improving the existing intellectual property courses, corresponding practical courses need to set up according to the differences in the categories and levels of intellectual property talents, so as to strengthen the practical skills training of intellectual property talents and enhance the practical ability of intellectual property talents. We must to innovate teaching methods of intellectual property talent training, and adopt classroom teaching, experiment teaching, teaching with engineering practice, innovation 
practice, and other linkage teaching. By using of the latest technology, overall cohesion of "theoretical study, practical skills training, professional practice through employment" would be achieved, and the new teaching method of complementary advantages would be formed.

\section{Summary}

Intellectual property is the soul of innovation and talent training is the foundation of a strong country. As the foundation of the development of intellectual property undertaking in China, intellectual property talents provide important support for innovation activities, which are an important guarantee for realizing the goal of a powerful intellectual property nation. From now on, we should value and innovate the training mode of intellectual property talents, and accelerate the training of high-quality intellectual property talents. We need to provide better services for the creation, use, protection, management and service of intellectual property, and further implement the innovation-driven development strategy.

\section{References}

[1] G. Wang, J. Ma, Analysis on training model of intellectual property personnel in an enterprise. International Business and Management, Vol.8, No.2, pp.214-219, 2014.

[2] Y. Zheng, China's intellectual property mechanism of talents training system existing problems and solutions. Electronics Intellectual Property, pp.43-45, 2008.

[3] M. Chen, Thinking on Chinese university intellectual property education and professionals' cultivation. Intellectual Property, Vol.16, No.1, pp.3-10, 2006.

[4] D. Tang, F. Feng, Intellectual property talents in Chinese universities: evolution, problems and counter measures, Journal of Nanjing University of Science and Technology (Social Sciences Edition), vol.32, pp.27-31+72, 2019.

[5] P. Xia, Research on training condition of Chinese intellectual property professionals. In: Zhang J. (eds) Applied Informatics and Communication. ICAIC 2011. Communications in Computer and Information Science, vol.226. pp.205-214, 2011. 